\title{
Pengaruh Penggunaan Mind Map terhadap Pemahaman Konsep Stoikiometri
}

\author{
Andi Suhardi ${ }^{1}$, Laily Yunita Susanti ${ }^{2}$, Susilawati ${ }^{3}$ \\ ${ }^{1,2}$ Program Studi Tadris IPA, Institut Agama Islam Negeri Jember \\ ${ }^{3}$ Program Studi Tadris IP A, Universitas Islam Negeri Sultan Syarif Kasim Rian \\ e-mail: \\ ${ }^{1}$ suhardi@iain-jember.ac.id \\ 2 laily@iain-jember.ac.id \\ ${ }^{3}$ susilawati@uin-suska.ac.id
}

\begin{abstract}
This study examines the effect of using mind map on understanding the stoichiometric concepts of students in basic chemistry courses. This research is a quasi-experimental study using a nonequivalent pretest-posttest control group design. The research subjects consisted of 80 students. The research instrument was a test instrument to measure the ability to understand the stoichiometric concepts of students in basic chemistry courses. The results showed that the average value of the understanding of the stoichiometric concept of students learning to use mind map at 85.50 was greater than the average value of the stoichiometric concept of students learning using lectures with a value of 80.35 . This shows that understanding the stoichiometric concepts of students who learn using mind map media is higher than students who study with the lecture method. Based on these results it can be concluded that learning using mind map is more effective than the lecture method on the ability to understand the stoichiometric concepts of students.
\end{abstract}

Keywords: mind map, stoichiometric concept understanding.

\begin{abstract}
ABSTRAK
Penelitian ini menguji pengaruh penggunaan mind map terhadap pemahaman konsep stoikiometri mahasiswa pada mata kuliah kimia dasar. Penelitian ini merupakan penelitian eksperimen semu dengan menggunakan rancangan nonequivalent pretest-posttest control group design. Subjek penelitian terdiri atas 80 mahasiswa. Instrumen penelitian berupa instrumen tes untuk mengukur kemampuan pemahaman konsep stoikiometri mahasiswa pada mata kuliah kimia dasar. Hasil penelitian menunjukkan nilai rata-rata pemahaman konsep stoikiometri mahasiswa yang belajar menggunakan mind map sebesar 85,50 lebih besar daripada nilai rata-rata pemahaman konsep stoikiometri mahasiswa yang belajar menggunakan ceramah dengan nilai 80,35. Hal ini menunjukkan bahwa pemahaman konsep stoikiometri mahasiswa yang belajar menggunakan media mind map lebih tinggi dibandingkan mahasiswa yang belajar dengan ceramah. Hasil penelitian ini dapat disimpulkan bahwa pembelajaran dengan menggunakan mind map lebih efektif dibandingkan metode ceramah terhadap kemampuan pemahaman konsep stoikiometri mahasiswa.
\end{abstract}

Kata kunci: mind map, pemahaman konsep stoikiometri. 


\section{PENDAHULUAN}

Salah satu rumpun bidang sains yang dipelajari adalah Kimia. Materi kimia tersusun dari yang sederhana sampai yang kompleks secara berurutan (Yager, R.E. \& Razali, 1994). Karakteristik dari ilmu kimia yaitu konsep yang disajikan bersifat abstrak, umunya konsep sudah sederhanakan dari keadaan sebenarnya, serta konsep dalam kimia disajikan saling berkaitan dan sistematis. Berdasarkan karakteristik tersebut, sangat memungkinkan menjadikan kimia salah satu pelajaran yang dainggap sulit oleh siswa maupun mahasiswa, yang terjadi secara konsisten dengan sumber tertentu sehingga berdampak pada siswa mengalami kekeliruan terhadap konsep. Diantara penelitian tentang kesalahan konsep pada materi kimia diantaranya yang disebutkan oleh (Syahrial, 2010) yang menunjukkan bahwa mahasiswa calon guru kimia masih mengalami kesalahan konsep pada materi ikatan kovalen, penelitian senada diungkapkan oleh (Suwolo, 2005) tentang mahasiswa yang mengalami kesalahan konsep pada materi ikatan kovalen, dan selanjutnya (Winarni, 2006) menyebutkan kesalahan konsep dialami mahasiswa kimia pada materi gaya antar molekul. Dari beberapa permasalahan pembelajaran kimia tersebut, masih berpangkal pada metode dan media yang digunakan dosen dalam pembelajaran.

Salah satu alasan utama mahasiswa menemukan banyak kesulitan dalam belajar kimia adalah tingkat abstraksi dari konsep ini, dan para dosen sering tidak memiliki sumber daya yang diperlukan untuk membuatnya lebih konkrit melalui laboratorium demonstrasi dan eksperimen. Menurut Njoku (2015), semakin tinggi konsep hirarki dari konsep-konsep teoritis, semakin sulit bagi siswa untuk memahami materi. Ini karena konsep teoritis yang lebih rendah harus dipelajari terlebih dahulu untuk mengembangkan latar belakang yang cukup kuat untuk mempelajari konsep yang lebih tinggi.

Sumber kesulitan lain dalam pembelajaran kimia adalah ketidakmampuan peserta didik memahami tiga tingkat fenomena kimia (Onwu, G.O.M., and Randall, 2006). Ketiga tingkat ini adalah makroskopis, sub-mikroskopis, dan simbolik. Tingkat makroskopis adalah nyata dan konkrit, dalam bentuk kegiatan kimia seperti percobaan yang terlihat, dan peserta didik dapat melihat perubahan serta produk yang dihasilkan. Tingkat sub-mikroskopis melibatkan partikel tak terlihat seperti atom, ion, molekul, elektron, proton, dan neutron. Partikel-partikel ini hanya bisa dibayangkan oleh peserta didik, dapat digambarkan dengan instrumental melalui imajinasi peserta didik. Terakhir tingkat simbolik adalah bahasa kimia yang dinyatakan sebagai simbol, rumus, persamaan, representasi bergambar, grafik dan representasi matematis (Sirhan, 2007).

Salah satu materi kimia yang diajarkan pada mahasiswa adalah stoikiometri. Materi stoikiometri mencakup dua aspek, yaitu konseptual dan algoritmik. Soal-soal algoritmik lebih sering diujikan oleh guru dalam pembelajaran untuk mengukur pemahaman siswa pada materi stoikiometri dibandingkan dengan soal-soal yang bersifat konseptual, karena banyak pendapat yang mengatakan bahwa pemahaman algoritmik yang mengukur tentang pemahaman terhadap prosedur dalam pemecahan masalah kimia akan menunjukkan pemahamannya secara konseptual. Hal ini berdampak pada pemahaman algoritmik siswa lebih baik jika dibandingkan pemahaman konseptualnya sebagaimana hasil penelitian yang diungkapkan oleh (Istiqomah, 2012) bahwa siswa cenderung mengalami kesulitan dalam menyelesaikan masalah konseptual dibandingkan dengan masalah algoritmik.

Upaya memperbaiki kesalahan konsep materi kimia yang dialami siswa dapat dilakukan melalui pembelajaran dengan menggunakan teknik mencatat mind map. Alat mapping itu terdiri dari mind mapping, concept mapping dan argument mapping (Davies, 2010). Mind mapping dapat digunakan sebagai alat bantu agar siswa dapat menggambarkan dan mengaitkan antar konsep. Sementara concept map adalah alat yang digunakan tidak hanya untuk agar siswa mengerti hubungan antar konsep, tetapi juga mengerti terhadap konsep, dan domain yang mereka punyai. Sedangkan argument concept memiliki peran lebih dalam membantu siswa untuk melihat hubungan inferensial antara proposisi dan konten serta mengecek akurasi suatu kesimpulan (Davies, 2010). 
Concept map merupakan suatu variasi dari mind mapping. Pada concept map judul topik terletak pada paling atas kemudian disusun ke bawah secara hirarki. Concept map merupakan suatu peta yang menjelaskan konsep dengan memakai urutan tingkatan atau hirarki dan tersusun dari judul kemudian turun ke arah bawah subtopik sampai ke ujung (Meier, 2007). Concept map didefenisikan sebagai suatu alat berbentuk grafik yang merepresentasikan dan menggambarkan pengertian dan pemahaman menjadi sebuah konsep (Torre, M., Daley, B., Schweitzer, T., Sidharta, S., Petkova, J., Ziebert, 2007). Concept map ini dikembangkan oleh Novak and Gowin berdasarkan teori asimilasi pembelajaran oleh Ausubel (Daley, BJ., Torre, 2010). Sedangkan argument mapping lebih berfokus pada mengembangkan struktur dari kesimpulan (Davies, 2010). Semua variasi itu bermanfaat untuk meningkatkan kualitas proses dan hasil belajar.

Untuk memperbaiki kesalahan konsep pada kajian ini digunakan alat bantu dalam bentuk mind map. Cara kerja teknik ini dengan cara mengoptimalkan kerja otak melalui kesan yang ditimbulkannya dengan memanfaatkan citra visual dan prasarana grafis lainnya. Mind mapping ini menggunakan keterampilan kortikal kata, gambar, nomor, logika, ritme, warna dan ruang kesadaran dalam satu cara unik yang kuat. Sehingga siswa dapat mengeksplorasi seluas-luasnya apa yang ada dalam pikirannya. Pada prinsipnya, ada dua kegiatan pokok dalam model pembelajaran mind mapping, yaitu kegiatan memikir (mind) dan kegiatan memaparkan hasil secara serentak (mapping).

Namun, pemanfaatan mind map dalam pembelajaran harus mempertimbangkan karakteristik materi yang diajarkan. Sebagaimana yang disebutkan oleh (Abdolihi, M., Jvadnia, F., Bayat, D., Ghorbani, R., Ghanbari, A., Ghodosi, 2010) bahwa mind mapping jika digunakan dalam pengajaran anatomi lebih efektif meningkatkan pemahaman konsep dibandingan metode tradisional. Penggunaan mind map lebih efektif dalam memberi informasi yang didapat secara tertulis dari pada metode mandiri (Farran, P., Hussain, F., Hannessy, 2002). Belajar dengan mind map lebih fokus pada keaktifan dan aktivitas kreatif siswa. Ini akan meningkatkan kemampuan mereka untuk menghafal dan memperkuat pemahaman konsep siswa, dan meningkatkan kemampuan berpikir kreatif mereka (Fatmawati, 2016).

Berdasarkan latar belakang dan kajian teori maka terlihat bahwa mind map merupakan salah satu cara yang dapat digunakan untuk membantu memperbaiki kesalahan konsep mahasiswa untuk memperbaiki pemahamannya, dalam kajian ini pada materi stoikiometri. Sehingga, pada penelitian ini memfokuskan kajian pada pengaruh mind map terhadap pemahaman konsep pada materi stoikiometri. Sehingga tujuan penelitian ini adalah mengetahui pengaruh pembelajaran dengan menggunakan mind map terhadap pemahaman konsep mahasiswa pada mata kuliah Stoikiometri.

\section{METODE PENELITIAN}

Penelitian ini menggunakan desain eksperimen semu (quasi experiment) dengan rancangan nonequivalent pretest-posttest control group design. Dalam penelitian ini terdapat dua kelompok yaitu kelompok eksperimen dan kelompok kontrol. Kelompok eksperimen merupakan kelompok yang mendapatkan perlakuan menggunakan mind map dalam pembelajaran, sedangkan kelompok kontrol adalah kelompok yang tidak mendapatkan perlakuan (ceramah). Sebelum proses pembelajaran dimulai, kedua kelompok mendapatkan tes awal yang sama. Setelah itu, kelompok eksperimen mendapatkan perlakuan menggunakan mind map, sedangkan kelompok kontrol tanpa menggunakan mind map atau ceramah. Setelah proses pembelajaran selesai, masing-masing kelompok akan mendapatkan tes akhir yang sama. 
Tabel 1. Desain non-equivalent pretest-poestest control group

\begin{tabular}{cccc}
\hline Kelompok & Pretest & Perlakuan & Posttest \\
\hline Eksperimen & $\mathrm{O}_{1}$ & $\mathrm{X}$ & $\mathrm{O}_{2}$ \\
\hline Kontrol & $\mathrm{O}_{3}$ & - & $\mathrm{O}_{4}$ \\
\hline
\end{tabular}

Keterangan:

$\mathrm{O}_{1} \quad$ : $\quad$ Pretest pada kelompok eksperimen

$\mathrm{O}_{2} \quad$ : $\quad$ Posttest pada kelompok eksperimen

$\mathrm{O}_{3} \quad$ : $\quad$ Pretest pada kelompk kontrol

$\mathrm{O}_{4} \quad: \quad$ Posttest pada kelompok kontrol

$\mathrm{X} \quad$ : $\quad$ Perlakuan pada kelompok eksperimen

\section{Subyek Penelitian}

Populasi penelitian adalah mahasiswa IAIN Jember pada Program Studi Tadris IPA semester II tahun pelajaran 2017/2018. Sampel penelitian sebanyak 80 mahasiswa dari 2 kelas yang memiliki kemampuan awal sama, satu kelas dijadikan sebagai kelompok eksperimen dan satu kelas yang lain digunakan sebagai kelompok kontrol.

\section{Instrumen}

Instrumen yang digunakan dalam penelitian ini berupa tes pemahaman konsep stoikiometri mahasiswa pada mata kuliah kimia dasar. Instrumen tes terdiri dari 20 butir soal yang disusun dalam bentuk pilihan ganda disajikan dalam bentuk pretest dan posttest. Untuk mendapatkan validitas dari instrumen tersebut dilakukan uji validitas dan reliabilitas instrumen baik melalui expert judgement dari ahli isi dan ahli materi. Data yang terkumpul dianalisis menggunakan uji statistik Anova dengan bantuan SPSS 24.0 for windows. Instrumen yang dipakai telah divalidasi dan hasil uji reliabilitas menunjukkan keofisien alpha-Cronbach tes pemahaman konsep stoikiometri adalah 0,866. Dengan demikian, tes pemahaman konsep stoikiometri memiliki reliabilitas sangat tinggi.

\section{Analisis Data}

Analisis data dilakukan untuk menjawab rumusan masalah dan menguji hipotesis, untuk menguji hipotesis diterima atau ditolak menggunakan uji perbedaan dua rata-rata. Uji yang digunakan adalah uji-t. Namun sebelum dilakukan pengujian hipotesis dengan uji-t, maka perlu dilakukan uji prasyarat analisis terlebih dahulu. Uji prasyarat yang perlu dilakukan adalah uji normalitas dan uji homogenitas untuk memeriksa keabsahan sampel sebagai prasyarat dapat dilakukan analisis data.

\section{HASIL DAN PEMBAHASAN}

\section{Uji Homogenitas Pre Test}

Analisis data hasil penelitian dimulai dengan analisis data hasil pretes untuk pemahaman konsep mahasiswa tentang materi stoikiometri. Analisis digunakan untuk menentukan homogenitas kemampuan awal tentang materi yang dipelajari mahasiswa selama proses penelitian. Uji homogenitas hasil pretes dapat dilihat pada Tabel 2. 
Tabel 2. Uji homogenitas hasil pretest

\begin{tabular}{|c|c|c|c|c|c|c|c|c|}
\hline \multicolumn{9}{|c|}{ Descriptives } \\
\hline \multicolumn{9}{|c|}{ Konsep Stoikiometri } \\
\hline & & & \multicolumn{6}{|c|}{$95 \%$ Confidence Interval for } \\
\hline & \multicolumn{4}{|c|}{ Std. } & \multicolumn{2}{|c|}{ Mean } & \multirow[b]{2}{*}{ Minimum } & \multirow[b]{2}{*}{ Maximum } \\
\hline & $\mathrm{N}$ & Mean & Deviation & Std. Error & Lower Bound & Upper Bound & & \\
\hline Mind Map & 40 & 67,65 & 6,036 & 954 & 65,72 & 69,58 & 56 & 76 \\
\hline Ceramah & 40 & 67,63 & 7,561 & 1,195 & 65,21 & 70,04 & 55 & 84 \\
\hline Total & 80 & 67,64 & 6,798 & ,760 & 66,12 & 69,15 & 55 & 84 \\
\hline
\end{tabular}

Tabel 3. Test of Homogeneity of Variances

\begin{tabular}{|c|c|c|c|}
\hline \multicolumn{4}{|c|}{ Konsep Stoikiometri } \\
\hline Levene Statistic & df1 & $\mathrm{df} 2$ & Sig. \\
\hline 1,466 & 1 & 78 & 230 \\
\hline
\end{tabular}

Berdasarkan uji homogenitas pada kedua kelompok, baik pada kelompok eksperimen dengan menggunakan media mind map, maupun pada kelompok kontrol tanpa menggunakan media (ceramah), menunjukkan nilai signifikan 0,230 lebi besar dari 0,05. Artinya pada kedua kelompok sampel sebelum memperoleh perlakuan memiliki kemampuan yang sama atau homogen.

\section{Uji Asumsi Hasil Belajar (Post Test)}

Uji asumsi dilakukan untuk memeriksa distribusi data, varian antar kelompok. Uji asumsi pertama yang dilakukan adalah uji normalitas data, dan kedua adalah homogenitas varian.

\section{Uji Normalitas Data Variabel Terikat}

Uji normalitas data dilakukan pada dua kelompok sampel yang terdiri atas satu kelompok sampel dengan pembelajaran mind map dan satu kelompok sampel dengan pembelajaran Ceramah. Hasil uji normalitas data untuk variabel terikat berdasarkan metode pembelajaran disajikan pada tabel 4

Tabel 4. Hasil uji normalitas sebaran data menurut pengelompokan metode pembelajaran

\begin{tabular}{|c|c|c|c|c|c|c|c|}
\hline \multicolumn{8}{|c|}{ Tests of Normality } \\
\hline & & \multicolumn{3}{|c|}{ Kolmogorov-Smirnov ${ }^{\mathrm{a}}$} & \multicolumn{3}{|c|}{ Shapiro-Wilk } \\
\hline & Metode Belajar & Statistic & Df & Sig. & Statistic & df & Sig. \\
\hline Konsep & MInd Map & ,118 & 40 & ,171 & ,946 & 40 & ,056 \\
\hline Stoikiometri & Ceramah & 136 & 40 & ,059 & 957 - r - & 40 & 131 \\
\hline
\end{tabular}

a. Lilliefors Significance Correction

Berdasarkan Tabel 4 data kelompok dengan pembelajaran mind map terdistribusi normal dengan nilai statistik Kolmogorov-Smirnov untuk variabel terikat pemahaman konsep stoikiometri 0,118 dengan angka signifikansi $(\alpha)$ 0,171 lebih besar dari 0,05. Demikian pula, data kelompok sampel dengan pembelajaran ceramah untuk variabel terikat pemahaman konsep stoikiometri 
terdistribusi normal dengan nilai statistik Kolmogorov-Smirnov 0,136 dengan angka signifikansi ( $\alpha$ ) 0,059 lebih besar dari 0,05.

\section{Uji Homogenitas Varian Antar Kelompok}

Uji homogenitas varian antar kelompok menggunakan statistik Levene. Hasil uji homogenitas varian antar kelompok variabel terikat berdasarkan metode pembelajaran yang diterapkan disajikan pada Tabel 5

Tabel 5. Hasil uji homogenitas varian antar kelompok metode pembelajaran

\begin{tabular}{|c|c|c|c|c|c|c|c|c|}
\hline \multicolumn{9}{|c|}{ Descriptives } \\
\hline \multicolumn{9}{|c|}{ Konsep Stoikiometri } \\
\hline & \multirow[b]{2}{*}{$\mathrm{N}$} & \multirow[b]{2}{*}{ Mean } & \multirow[b]{2}{*}{ Std. Deviation } & \multirow[b]{2}{*}{ Std. Error } & \multicolumn{2}{|c|}{$\begin{array}{l}95 \% \text { Confidence } \\
\text { Interval for Mean }\end{array}$} & \multirow[t]{2}{*}{ Minimum } & \multirow[t]{2}{*}{ Maximum } \\
\hline & & & & & $\begin{array}{l}\text { Lower } \\
\text { Bound }\end{array}$ & $\begin{array}{l}\text { Upper } \\
\text { Bound }\end{array}$ & & \\
\hline Mind Map & 40 & 85,50 & 3,479 & ,550 & 84,39 & 86,61 & 80 & 92 \\
\hline Ceramah & 40 & 80,35 & 2,983 & 472 & 79,40 & 81,30 & 75 & 86 \\
\hline Total & 80 & 82,93 & 4,133 & 462 & 82,01 & 83,84 & 75 & 92 \\
\hline
\end{tabular}

Tabel 6. Test of Homogeneity of Variances

\begin{tabular}{|c|c|c|c|}
\hline \multicolumn{4}{|c|}{ Test of Homogeneity of Variances } \\
\hline \multicolumn{4}{|c|}{ Konsep Stoikiometri } \\
\hline Levene Statistic & df1 & $\mathrm{df} 2$ & Sig. \\
\hline, 502 & 1 & 78 & ,481 \\
\hline
\end{tabular}

Berdasarkan Tabel 6 tampak bahwa semua nilai statistik Levene menunjukkan angka signifikansi lebih besar dari 0,05. Ini berarti, hipotesis nol yang menyatakan "varian antar kelompok untuk kedua variabel terikat berdasarkan metode pembelajaran tidak bebeda", diterima. Dengan kata lain, bahwa varian antar kelompok untuk variabel terikat berdasarkan metode pembelajaran adalah homogen.

\section{Pengujian Hipotesis}

Pengujian hipotesis dilakukan menggunakan uji beda (t-test) untuk menguji adanya perbedaan pemahaman konsep mahasiswa berdasarkan metode yang berbeda. Hasil pengujian selengkapnya disajikan dalam Tabel 7

Tabel 7. Ringkasan hasil uji beda (t-test) pemahaman konsep post-tes

\section{Independent Samples Test}

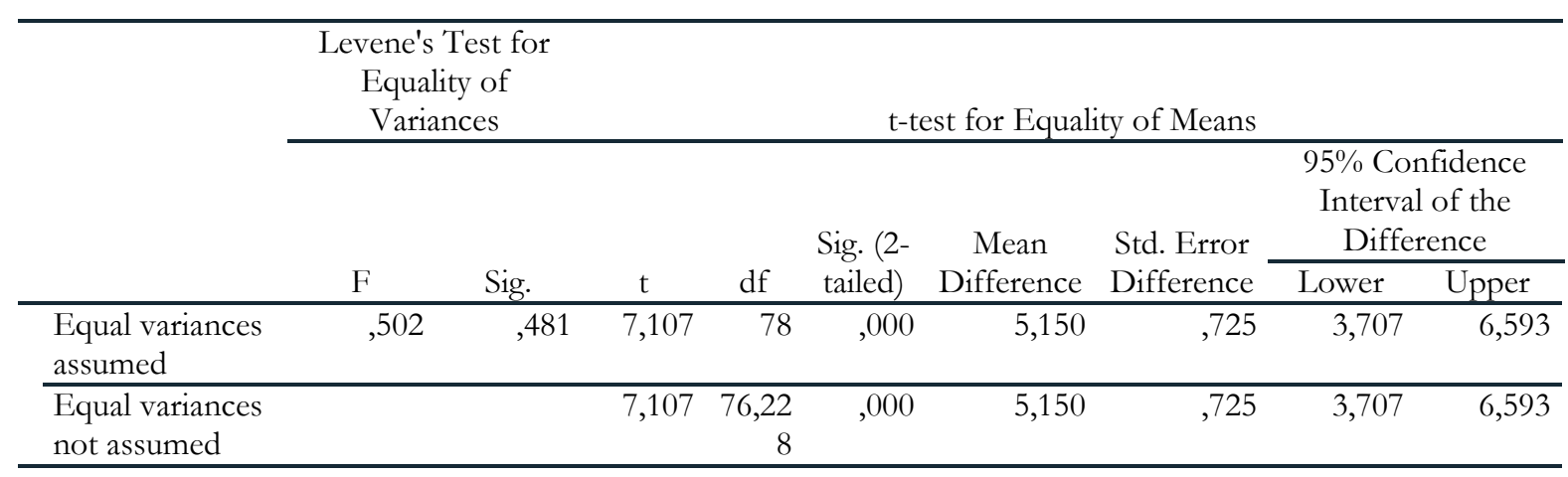


Berdasarkan Tabel 7 pengaruh variabel bebas terhadap variabel terikat pemahaman konsep dapat ditarik kesimpulan pengaruh variabel bebas metode pembelajaran terhadap pemahaman konsep stoikiometri, diperoleh nilai statistik dengan angka signifikansi 0,000, lebih kecil dari 0,05. Hasil analisis ini digunakan untuk mengambil keputusan hipotesis alternatif (Ha) bahwa ada perbedaan skor rata-rata pemahaman konsep stoikiometri antara kelompok metode pembelajaran mind map dan pembelajaran Ceramah, diterima. Dengan demikian, pada taraf signifikansi 0,05 variabel pemahaman konsep dipengaruhi oleh metode pembelajaran.

Hasil penelitian menunjukkan bahwa penggunaan mind map memberikan perbedaan signifikan terhadap pemahaman konsep stoikiometri mahasiswa dibanding pembelajaran ceramah. Dengan menggunakan mind map, mahasiswa dapat secara mudah menguraikan konsep-konsep stoikiometri ke dalam konsep yang lebih sederhana.

Analisis pengaruh penggunaan mind map terhadap pemahaman konsep mahasiswa menggunakan statistik uji beda (t-test) dengan taraf signifikansi $(\alpha)$ sebesar $5 \%$ atau 0,05 . Dari hasil analisis SPSS diperoleh nilai signifikansi $0,000 \leq 0,05$. Dengan demikian hipotesis Ha diterima, dan hipotesis Ho ditolak, sehingga dapat disimpulkan bahwa terdapat pengaruh positif penggunaan mind map terhadap pemahaman konsep stoikiometri mahasiswa. Hasil ini sejalan dengan pendapat (Imaduddin, M. C., \& Utomo, 2012) bahwa pembelajaran dengan metode mind mapping berpengaruh positif terhadap peningkatan prestasi belajar dibandingkan dengan pembelajaran dengan secara konvensional. Selain itu, juga menurut (Rahayu, R., Suyitno, A., \& Sugiharti, 2012) menyatakan bahwa mind mapping dapat meningkatkan hasil belajar dan mengatasi miskonsepsi. Pembelajaran berbantuan mind map memungkinkan mahasiswa lebih fokus pada pokok bahasan yang dipelajari. Pola pikir mahasiswa akan lebih berkembang dengan memunculkan ide-ide dalam proses pembelajaran sehingga proses pembelajaran yang berbantuan mind map dapat meningkatkan hasil belajar.

Ada beberapa kelebihan mind map dalam membantu mahasiswa memahami konsep: (1) membantu mahasiswa untuk berkosentrasi (memusatkan perhatian) dan lebih baik dalam mengingat, (2) meningkatkan kecerdasan visual dan keterampilan observasi, (3) melatih kemampuan berpikir kritis dan komunikasi, (4) meningkatkan kreativitas dan daya cipta, (5) melatih inisiatif dan rasa ingin tahu, (6) meningkatkan kecepatan berpikir dan mandiri, (7) membantu pengungkapan diri serta merangsang pengungkapan pikiran, (8) menghemat waktu sebaik mungkin (Olivia, 2009).

Dalam mind map, salah satu kunci konsep, sering direpresentasikan sebagai gambar, terletak di tengah halaman. Dari topik sentral ini, beberapa topik terkait topik utama dalam berbagai warna terpancar keluar dalam bentuk cabang tebal. Terlampir pada cabang-cabang utama ini, lainnya cabang yang lebih kecil mewakili konsep terkait. Dengan cara ini, kata-kata terkait dihubungkan melalui kurva utama dan sub cabang. Mind map dapat lebih diperkaya dengan warna, gambar, kode, panah, dan dimensi untuk mencerminkan minat pribadi dan individualitas (Buzan, 2005). Karakteristik mind map yang spesifik didasarkan dan didukung oleh temuan penelitian baik dari penelitian pendidikan maupun otak (Budd, 2004). Merujuk pada beberapa penelitian di atas menunjukkan bahwa mind map efektif dalam membantu anak menyusun, merangkum, dan mempelajari materi pelajaran (Brinkmann, 2003). Bagi mahasiswa, mind map dapat membantu mahasiswa untuk mengaktifkan otak agar memberi gambaran jelas dan terperinci, membantu mengelompokkan konsep dan membandingkannya, serta membantu mahasiswa untuk memusatkan perhatian pada pokok bahasan (Buzan, 2010)

\section{SIMPULAN}

Berdasarkan hasil uji hipotesis penelitian tentang pengaruh penggunaan mind map terhadap pemahaman konsep stoikiometri mahasiswa pada mata kuliah kimia dasar dengan menggunakan 
uji-beda (t-test) diperoleh harga $t_{\text {hitung }}=7,107$ dengan menggunakan interpolasi, untuk taraf signifikansi $\alpha=0,05$ dan derajat kebebasan $\mathrm{db}=78$, diperoleh nilai $\mathrm{t}_{\text {tabel }}=1,665$. sehingga $\mathrm{t}_{\text {hitung }}$ berada di luar daerah penerimaan Ho, atau dengan kata lain Ho ditolak. Setelah melakukan proses pembelajaran dengan menggunakan metode yang telah ditentukan pada kelompok eksperimen maupun kelompok kontrol diperoleh temuan bahwa nilai rata-rata hasil posttest kelompok eksperimen $(85,50)$ lebih tinggi dari nilai rata-rata pada kelompok kontrol $(80,35)$. Dari hasil pengujian hipotesis, maka dapat diambil kesimpulan bahwa ada perbedaan signifikan antara nilai rata-rata pemahaman konsep stoikiometri mahasiswa yang diajarkan dengan menggunakan mind map dengan nilai rata-rata hasil pemahaman konsep stoikiometri mahasiswa yang diajarkan dengan menggunakan ceramah. Dengan demikian, terdapat pengaruh signifikan terhadap pemahaman konsep stoikiometri setelah menggunakan mind map.

Berdasarkan hasil penelitian ini maka dapat dilakukan kajian berikut terhadap materi yang memiliki karakteristik yang sama untuk melihat aspek lain dari hasil belajar siswa yang berkaitan erat dengan kelebihan mind map seperti kreatifitas mahasiswa. Oleh karena itu, disarankan dalam pemanfaatan teknik ini guru/dosen dapat mempertimbangkan pemilihan materi yang tepat untuk mengelompokkan konsep yang akan dihubungkan, dan sangat tidak disarankan untuk materi yang bersifat algoritmik atau prosedural.

\section{REFERENSI}

Abdolihi, M., Jvadnia, F., Bayat, D., Ghorbani, R., Ghanbari, A., Ghodosi, B. (2010). Mind Map Teaching Gross Anatomi is Sex Dependent. International Journal Mhorpology, 29(1), 41-44.

Brinkmann, A. (2003). Graphical Knowledge Display - Mind Mapping and Concept Mapping as Efficient Tools in Mathematics Education. Mathematics Education Review, 16, 35-48.

Budd, J. W. (2004). Mind Maps as Classroom Exercises. Journal of Economic Education, 35(1), 3546.

Buzan, T. (2005). The Ultimate Book of Mind Maps. London: Thorsons.

Buzan, T. (2010). Buku Pintar Mind Map. Jakarta: PT. Gramedia Pustaka Utama.

Daley, BJ., Torre, M. (2010). Concept Maps in Medical Education: an Analytical Literature Review. Medical Education, 44, 440-448.

Davies, M. (2010). Concept Mapping, Mind Mapping, Argument Mapping: What are the Differentces and Do the Matter? High Edu. Springer. https://doi.org/DOI.10.1007/s10734010-9387-6

Farran, P., Hussain, F., Hannessy, E. (2002). The Efficacy of the "Mind Map" Study Technique. Medical Education, 36, 426-443.

Imaduddin, M. C., \& Utomo, U. H. (2012). Efektifitas Metode Mind Mapping untuk Meningkatkan Prestasi Belajar Fisika pada Siswa Kelas VIII. Humanitas, 9(1), 62-75.

Istiqomah. (2012). Diagnosis Kesulitan Belajar Siswa pada Materi Stoikiometri dan Upaya Mengatasinya dengan Pembelajaran Problem Solving Kontekstual. Program Studi Pendidikan Kimia Pascasarjana Universitas Negeri Malang.

Meier, P. (2007). Mind-Mapping: a Tool for Eliciting and Representing Knowledge Held by 
Diverse Informants. Sosial Research Update, University of Surrey, 52.

Olivia, F. (2009). Gembira Belajar dengan Mind Mapping. Jakarta: PT Elex Media Komputindo.

Onwu, G.O.M., and Randall, E. (2006). Some Aspects of Students' Understanding of a Representational Model of the Particulate Nature of Matter in Chemistry in Three Different Countries. Chemistry Education Research and Practice, 7(4), 226-239.

Rahayu, R., Suyitno, A., \& Sugiharti, E. (2012). Keefektifan Pembelajaran Kooperatif Model Mind Mapping Berbantuan CD Pembelajaran terhadap Hasil Belajar. Unnes Journal of Mathematics Education, 1(1), 45-51.

Sirhan, G. (2007). Learning Difficulties in Chemistry: An Overview. Journal of Turkish Science Education, 4(2), 2.

Suwolo, T. . (2005). Identifikasi Kesalahan Konsep Ikatan Kovalen pada Mabasiswa Jurusan Pendidikan Kimia Universitas Negeri Gorontalo dan Upaya Memperbaikinya dengan Menggunakan Model Molekul. Pascasarjana Universitas Negeri Malang.

Syahrial, W. \&. (2010). Analisis Kesalaban Konsep Ikatan Kimia pada Mabasiswa Program Studi Pendidikan Kimia FKIP Unsyiah. Banda Aceh.

Torre, M., Daley, B., Schweitzer, T., Sidharta, S., Petkova, J., Ziebert, M. (2007). A Qualitative Evaluation of Medical Student Learning with Concept Maps. Medicall Teacher, 29, 949-958.

Winarni, S. (2006). Koreksi Kesalahan Konsep Gaya Antarmolekul (Intermolecular force)dengan Strategi Konflike Kognitif pada Mahasiswa Kimia Universitas Islam. Pascasarjana Universitas Negeri Malang.

Yager, R.E. \& Razali, S. . (1994). What College Chemistry Instructors and High School Chemistry Teachers Perceive as Important for Incoming College Students. Journal of Research in Science Teaching, 31(7), 735-747. 